\title{
Salinidade, sodicidade e propriedades microbiológicas de Argissolo cultivado com erva-sal e irrigado com rejeito salino
}

\author{
Célia Maria Maganhotto de Souza Silva(1), Rosana Faria Vieira ${ }^{(1)}$ e Pablo Roberto Oliveira ${ }^{(1)}$ \\ (1)Embrapa Meio Ambiente, Caixa Postal 69, CEP 13820-000 Jaguariúna, SP. E-mail: celia@cnpma.embrapa.br, rosana@cnpma.embrapa.br, \\ pabloliveira@yahoo.com.br
}

\begin{abstract}
Resumo - O objetivo deste trabalho foi avaliar o efeito da irrigação com rejeito da dessalinização, oriundo de tanques de produção de tilápia-rosa, sobre as propriedades químicas e microbiológicas de solos cultivados com erva-sal (Atriplex nummularia Lindl.). Quatro áreas foram usadas, das quais duas foram irrigadas com rejeito salino e cultivadas, durante um e cinco anos, com erva-sal. As outras duas áreas foram conduzidas sem irrigação: uma cultivada com vegetação natural e outra com a halófita. Avaliaram-se os parâmetros relativos à salinidade e sodicidade do solo, e também as seguintes características: carbono da biomassa microbiana (Cmic); relação Cmic/carbono orgânico; atividade das enzimas fosfatase ácida, fosfatase alcalina, beta-glucosidase, protease, L-asparaginase, L-glutaminase. A adição de sais afetou as propriedades físicas e químicas dos solos irrigados com rejeito salino, com tendência à salinização e sodificação. A salinidade afetou as propriedades microbiológicas nos solos irrigados, mas o cultivo da halófita favoreceu a produção das enzimas estudadas. O cultivo da erva-sal em áreas que recebem rejeito salino pela irrigação melhora a qualidade biológica dos solos e sua fertilidade, mas não impede a salinização.
\end{abstract}

Termos para indexação: Atriplex nummularia, carbono da biomassa microbiana, enzima do solo, propriedade física, propriedade química.

\section{Salinity, sodicity and microbiological properties of an Ultisol cultivated with saltbush and irrigated with saline effluents}

\begin{abstract}
The objective of this work was to evaluate the effects of irrigation with saline effluents, from red tilapia production ponds, on chemical and microbiological properties of soils cultivated with saltbush (Atriplex nummularia Lindl). Four areas were used, from which two were irrigated with saline waste and cultivated with A. nummularia, during one and five years. The other two areas were not irrigated, and one was cultivated with natural vegetation and the other with the halophyte. The parameters related to soil salinity and sodicity were evaluated, as well as the following characteristics: microbial biomass carbon (Cmic); Cmic/organic carbon; the activity of acid and alcaline phosphatase enzymes, beta-glucosidase, protease, L-asparaginase and L-glutaminase. The addition of salts affected the physical and chemical properties of the soils irrigated with saline effluents, with a tendency to salinization and sodification. The salinity affected the microbiological properties of irrigated soil, but the cultivation with the halophyte improved the production of the studied enzymes. A. nummularia cultivation in areas that received saline effluents from irrigation improves soil fertility and microbiological properties, but does not prevent salinity.
\end{abstract}

Index terms: Atriplex nummularia, carbon microbial biomass, soil enzymes, physical properties, chemical properties.

\section{Introdução}

Na zona rural do Semi-Árido do Nordeste brasileiro, é comum o aproveitamento de água salobra para o consumo humano após a dessalinização com equipamentos que retiram o excesso de sais da água e a divide em partes iguais de água potável e efluente altamente salino, com elevado potencial de contaminação ambiental (Soares et al., 2006). A destinação inadequada desse efluente trás sérios problemas ambientais.

O despejo indiscriminado desse efluente pode resultar em salinização do solo, como foi confirmado por Amorim et al. (1997), em Petrolina, PE. No Estado do Ceará, observou-se que $25 \%$ dos solos que receberam efluente salino apresentaram erosão e salinidade (Pessoa, 2000), o que demonstra a seriedade do problema. 
A ampla utilização de dessalinizadores, como acontece na região do Semi-Árido do Nordeste, associada à falta de alternativas de manejo dos efluentes salinos, pode causar danos ambientais, principalmente pelo aumento da salinidade e sodicidade do solo e pela contaminação dos mananciais subterrâneos (Porto et al., 2001; Azevedo et al., 2005).

Entre as alternativas para o uso de efluentes salinos, está a cristalização seletiva de sais (Amorim et al., 2004), irrigação de mudas cítricas (Soares et al., 2005), cultivo de tilápia-rosa (Oreochrimis sp.) e camarão (Porto et al., 2001; Azevedo etal.,2005). Nosúltimos casos, os animais reciclam parte do sal contido na água. Entretanto, como há necessidade de oxigenação constante, uma parcela da água do tanque deve ser substituída diariamente. Essa parcela de água proveniente dos tanques de criação de peixes e camarão (rejeito) pode ser utilizada para irrigar plantas, particularmente a halófita erva-sal (Atriplex nummularia Lindl.) utilizada como forragem e conhecida por sua alta tolerância a ambientes salinos (Porto et al., 2006). Além de tolerar a salinidade do solo, essa planta possui potencial para fitorremediar áreas salinizadas, uma vez que retira do solo grande quantidade de sal para uso em seu metabolismo. Ao se produzir $5 \mathrm{Mg}$ de matéria seca de erva-sal, extrai-se $1.000 \mathrm{~kg} \mathrm{ha}^{-1}$ de sal por ano do solo (Informações..., 2007). No entanto, segundo Porto et al. (2001), apesar dessa eficiência na retirada dos sais do solo, a remoção não é significativa quando comparada à quantidade de sais adicionada pela irrigação com água de alta salinidade. Com isso, o uso do rejeito dos tanques para irrigar a halófita pode resultar na salinização do solo, e acarretar efeitos adversos em suas propriedades químicas e físicas e em seus processos biológicos (Tejada \& Gonzalez, 2005).

De acordo com Liang et al. (2005), a salinização vem aumentando em diversas áreas do mundo. Há grande número de informações disponíveis na literatura sobre os efeitos da salinidade nas propriedades físicas e químicas do solo (Sardinha et al., 2003), porém aspectos microbiológicos são raramente estudados (Yuan et al., 2007).

Pereira et al. (2004) investigaram a atividade microbiana, em solos cultivados com erva-sal e irrigados com rejeito salino, e concluíram que a presença da halófita influencia positivamente a atividade microbiana do solo. No entanto, esses autores sugerem a continuidade dos estudos, para melhor entendimento dos processos e confirmação das tendências observadas.
O objetivo deste trabalho foi avaliar o efeito da irrigação com rejeito salino, oriundo de tanques de produção de tilápia-rosa, sobre as propriedades químicas e microbiológicas de um Argissolo cultivado com Atriplex nummularia Lindl.

\section{Material e Métodos}

O estudo foi conduzido no Campo Experimental da Caatinga, da Embrapa Semi-Árido, em Petrolina, PE. O solo é classificado como Argissolo Amarelo eutrófico abrúptico plíntico, com $10 \%$ de argila, $14 \%$ de silte e $76 \%$ de areia. $\mathrm{Na}$ área experimental, a precipitação pluvial média anual é de 400 a $600 \mathrm{~mm}$, distribuídos, principalmente, no verão. A temperatura média do ar situa-se entre 28 e $35^{\circ} \mathrm{C}$. A evapotranspiração potencial média anual é de aproximadamente $2.680 \mathrm{~mm}$. Durante o período da experimentação, a média pluviométrica no local foi de $395,2 \mathrm{~mm}$, exceto em 2004, quando a precipitação foi muito acima da média $(819,4 \mathrm{~mm})$, e cerca 50\% (431 mm) ocorreram no mês de janeiro.

Quatro áreas foram identificadas e amostradas: 1 - área sem irrigação, coberta com vegetação natural da caatinga; 2 - área sem irrigação, cultivada com erva-sal; 3 -área irrigada com rejeito salino e cultivada com erva-sal, durante um ano; 4 - área irrigada com rejeito salino e cultivada com erva-sal por cinco anos consecutivos. Nas duas últimas áreas, foram aplicados $300 \mathrm{~L}$ de rejeito salino por planta por semana, de uma só vez. Não houve adubação no cultivo da erva-sal.

$\mathrm{O}$ rejeito salino apresentou $\mathrm{pH}$ entre 6,7 e 8,1, com condutividade elétrica média de $9,32 \mathrm{dS} \mathrm{m}^{-1}$, quantidade média a alta de $\mathrm{Na}^{+}\left(49,88 \mathrm{mmol}_{\mathrm{c}} \mathrm{L}^{-1}\right)$, $\mathrm{Mg}^{2+}\left(32,67 \mathrm{mmol}_{\mathrm{c}} \mathrm{L}^{-1}\right)$ e $\mathrm{Ca}^{2+}\left(20,83 \mathrm{mmol}_{\mathrm{c}} \mathrm{L}^{-1}\right)$ e moderado teor de $\mathrm{K}^{+}\left(0,94 \mathrm{mmol}_{\mathrm{c}} \mathrm{L}^{-1}\right)$. O solo, inicialmente, apresentou os seguintes atributos químicos: pH 5,7; matéria orgânica, $5,9 \mathrm{~g} \mathrm{dm}^{-3}$; $\mathrm{P}$ disponível (Mehlich 1), 6,33 mg dm${ }^{-3} ; \mathrm{Na}^{+}, 0,21$ mmol $_{\mathrm{c}} \mathrm{L}^{-1}$; $\mathrm{Mg}^{2+}, 2,7 \mathrm{mmol}_{\mathrm{c}} \mathrm{L}^{-1} ; \mathrm{Ca}^{2+}, 2,8 \mathrm{mmol}_{\mathrm{c}} \mathrm{L}^{-1} ; \mathrm{e} \mathrm{K}^{+}$, $0,31 \mathrm{mmol}_{\mathrm{c}} \mathrm{L}^{-1}$.

De cada área, foram obtidas três amostras de solo, cada uma constituída por cinco subamostras obtidas aleatoriamente. Os solos foram coletados às profundidades $0-10$ e $10-20 \mathrm{~cm}$, sempre próximo às plantas, no caso dos cultivados com a halófita, em: abril/2005, final do período chuvoso; agosto/2005, estação seca; e março/2006, durante a estação chuvosa. Em laboratório, as amostras de solo foram peneiradas (malha $<2 \mathrm{~mm}$ ), acondicionadas em sacos de plástico e 
armazenadas a $4^{\circ} \mathrm{C}$ até a realização das análises. $\mathrm{O}$ pH e a condutividade elétrica (CE) foram medidos em suspensão solo:água $(1: 2,5 \mathrm{~m} / \mathrm{v})$ com eletrodo de vidro. Os teores de carbono orgânico, nitrogênio e fósforo no solo foram determinados conforme as instruções descritas em Embrapa (1999). As análises de carbono, fósforo e nitrogênio foram realizadas apenas no início e no final do período experimental.

Para a avaliação do efeito da aplicação contínua do rejeito sobre a salinidade e sodicidade do solo, foram determinados, para os tratamentos com irrigação (áreas 3 e 4), as seguintes características: condutividade elétrica (CE), razão de adsorção de sódio (RAS), percentual de sódio trocável (PST) e porosidade. As amostras analisadas foram coletadas durante os períodos 2001/2006 (área 4) e 2005/2006 (área 3), em diferentes profundidades $(0-30,30-60,60-90 \mathrm{~cm})$. Para o cálculo de RAS e PST, foram determinadas a capacidade de troca catiônica (CTC) (Tucker, 1954), os teores de cálcio, magnésio, sódio e potássio (Embrapa, 1999), e as densidades global (DA) e de partículas do solo (DR) (Embrapa, 1997). As seguintes equações foram usadas, para a obtenção dos atributos acima citados: $\mathrm{RAS}=\mathrm{Na}^{+} /\left[\left(\mathrm{Ca}^{2+}+\mathrm{Mg}^{2+}\right) / 2\right]^{0,5}$; PST $=100\left(\mathrm{Na}^{+} / \mathrm{CTC}\right) ; \%$ Porosidade $=100[1-(\mathrm{DA} /$ DR)]; em que $\mathrm{Na}^{+}, \mathrm{Ca}^{2+}$ e $\mathrm{Mg}^{2+}$ são os teores desses elementos no solo $\left(\mathrm{cmol}_{\mathrm{c}} \mathrm{kg}^{-1}\right)$.

$\mathrm{O}$ carbono da biomassa microbiana ( $\mathrm{Cmic}$ ) foi determinado pelo método de extração-fumigação, tendo-se considerado o fator de correção $\mathrm{kc}=0,38$ (Vance et al., 1987). Foram também quantificadas as atividades das enzimas envolvidas nos ciclos do carbono $(\mathrm{C})$, nitrogênio $(\mathrm{N})$ e fósforo $(\mathrm{P})$, pelos métodos descritos por Alef et al. (1995), fosfatases ácida e alcalina e protease; por Alef \& Nannipieri (1995a, 1995b), beta-glucosidase e protease; por Frankerberger \& Tabatabai (1991), L-asparaginase; e por Frankerberger \& Tabatabai (1995), L-glutaminase.

O delineamento estatístico foi o de blocos ao acaso, com três repetições. Os dados referentes aos parâmetros analisados foram submetidos à análise de variância, e as médias foram comparadas pelo teste DMS, a 5\% de probabilidade; as análises de correlação foram realizadas entre as variáveis microbiológicas. Foi usado o teste de Duncan "Multiple Range" para os resultados que apresentaram interação significativa entre tratamento e tempo.

\section{Resultados e Discussão}

A condutividade elétrica, a RAS e a PST sofreram alterações em razão da irrigação com o rejeito salino, em todas as profundidades avaliadas (Tabela 1). De acordo com Richards (1954), uma das características de um solo salino é apresentar condutividade elétrica (CE) maior que $4 \mathrm{dS} \mathrm{m}^{-1}$, o que não ocorreu na área 3 (irrigação com o rejeito por um ano), mas foi observado em todas as profundidades avaliadas da área 4, o que torna evidente o efeito salinizador do efluente, pela aplicação contínua ao solo.

A RAS aumentou pela aplicação do rejeito, tanto no tratamento com um ano de irrigação como no com cinco anos de irrigação. Isso era esperado, principalmente pela RAS observada no rejeito, de 9,6 $\mathrm{mmol} \mathrm{L}^{-1}$. Ayres \& Westcot (1985) consideram que efluentes com RAS entre 6 e $12 \mathrm{mmol} \mathrm{L}^{-1}$ apresentam severa restrição de uso em irrigação de culturas.

Além da RAS, a PST consiste em outro atributo relacionado à sodicidade do solo, e valores acima de $15 \%$ já indicam sodificação (Richards, 1954), o que ocorreu praticamente em todas as profundidades nos dois tratamentos com irrigação.

Sabe-se que o aumento da concentração de sódio trocável no solo pode resultar na expansão e dispersão de argila (Oster \& Shainberg, 1980), em razão da substituição de íons $\mathrm{Ca}^{2+}$ e $\mathrm{Mg}^{2+}$ por $\mathrm{Na}^{+}$, nos sítios de troca dos minerais, o que diminui a atração entre as partículas do solo (Richards, 1954). Assim, espera-se diminuição da porosidade do solo, o que, no entanto, não foi constatada (Tabela 1). Entretanto, é interessante lembrar que a dispersão de colóides é favorecida não só pela alta razão de adsorção de sódio, mas também pela baixa condutividade elétrica (Minhas \& Charma, 1986). A alta condutividade elétrica significa maior teor de íons polivalentes no solo, o que pode resultar em menor deslocamento desses pelo sódio, no complexo de troca, o que provavelmente ocorreu no presente estudo.

A irrigação com rejeito salino alterou atributos da camada superficial e de camadas mais profundas do solo, uma vez que os aumentos de CE, RAS e PST foram constatados até $90 \mathrm{~cm}$ de profundidade (Tabela 1). Esses resultados eram esperados, uma vezque ouso de efluentes que apresentam altas concentrações de sais e sódio tende a provocar a salinização e sodificação do solo (Piotrowska et al., 2006; Hati et al., 2007). Não foram encontrados, na literatura nacional, muitos estudos sobre os efeitos da irrigação com rejeito salino nas propriedades do solo, 
mas pode-se destacar o trabalho de Pereira et al. (2004), em que foram avaliadas alterações - principalmente as microbianas - em solo plantado com erva-sal e irrigado com rejeito salino. Esses autores também constataram aumento na condutividade elétrica, pela aplicação de resíduo salino.

O conteúdo de sal no solo variou com o regime hidrológico. No período de chuvas, houve a lixiviação dos sais das camadas superficiais e a conseqüente acumulação nas camadas mais profundas. No entanto, o mecanismo de redistribuição de solutos não levou a modificações significativas nos valores da CE, entre os tratamentos, quando consideradas as diferentes camadas do solo (Tabela 1). Tedeschi \& Dell'Aquila (2005) observaram que a acumulação dos sais, em camadas inferiores do solo, está relacionada à quantidade de $\mathrm{NaCl}$ aplicada com a irrigação.

$\mathrm{O}$ aumento da salinidade no solo afeta as plantas e a microbiota do solo (Sardinha et al., 2003; Wichern et al., 2006; Yuan, 2007). No presente trabalho, o Cmic variou significativamente com os tratamentos. Essa diferença esteve associada à época de coleta, em ambas as profundidades (Tabela 2). Na camada superficial $(0-10 \mathrm{~cm})$, os maiores valores de $\mathrm{Cmic}$ foram observados nas áreas 2 e 4, enquanto à profundidade de $10-20 \mathrm{~cm}$, o maior valor desse parâmetro foi observado na área 2 , em que se verificou aumento de aproximadamente $38 \%$, em relação à média do tratamento 4 . Embora os efeitos adversos da salinidade sobre o Cmic já tenham sido reportados na literatura (Mamilov et al., 2004; Rasul et al., 2006; Wichern et al., 2006), as variações observadas na $\mathrm{CE}$, no presente estudo, parecem não ter sido suficientemente altas para causar um impacto negativo mais pronunciado no $\mathrm{Cmic}(\mathrm{r}=0,33$, Tabela 3$)$. Segundo Chang et al. (2007), o conteúdo de matéria orgânica pode amenizar os efeitos adversos dos sais solúveis. A vegetação constitui a principal fonte de resíduos da fração orgânica do solo (Liu et al., 2003),

Tabela 1. Parâmetros físicos e químicos dos solos cultivados com Atriplex nummularia e irrigados com rejeito salino por um e cinco anos ${ }^{(1)}$.

\begin{tabular}{|c|c|c|c|c|c|c|c|}
\hline \multirow[t]{2}{*}{ Variáveis $^{(2)}$} & \multirow[t]{2}{*}{ Profundidade $(\mathrm{cm})$} & \multicolumn{2}{|c|}{ Irrigado por 1 ano } & \multicolumn{4}{|c|}{ Irrigado por 5 anos } \\
\hline & & $2005^{(3)}$ & 2006 & $2000^{(3)}$ & 2004 & 2005 & 2006 \\
\hline \multirow[t]{3}{*}{$\overline{C E}\left(\mathrm{dS} \mathrm{m}^{-1}\right)$} & $0-30$ & $0,10 \mathrm{~b}$ & $2,75 \mathrm{a}$ & $0,3 \mathrm{c}$ & $4,6 \mathrm{c}$ & $7,0 \mathrm{~b}$ & $11,5 \mathrm{a}$ \\
\hline & $30-60$ & $0,80 \mathrm{~b}$ & $3,25 \mathrm{a}$ & $0,6 \mathrm{c}$ & $5,4 \mathrm{~b}$ & $6,1 \mathrm{a}$ & $7,8 \mathrm{a}$ \\
\hline & $60-90$ & $0,80 \mathrm{~b}$ & $2,98 \mathrm{a}$ & $0,6 \mathrm{c}$ & $6,7 \mathrm{~b}$ & $7,2 \mathrm{~b}$ & $8,2 \mathrm{a}$ \\
\hline \multirow[t]{3}{*}{ 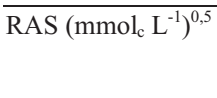 } & $0-30$ & $0,37 \mathrm{~b}$ & $13,75 \mathrm{a}$ & $0,2 \mathrm{c}$ & $7,4 \mathrm{~b}$ & $15,7 \mathrm{a}$ & $12,1 \mathrm{a}$ \\
\hline & $30-60$ & $0,44 \mathrm{~b}$ & $15,64 \mathrm{a}$ & $0,2 \mathrm{c}$ & $11,7 \mathrm{~b}$ & $15,2 \mathrm{a}$ & $12,6 b$ \\
\hline & $60-90$ & $0,36 \mathrm{~b}$ & $14,75 \mathrm{a}$ & $0,2 \mathrm{c}$ & $14,5 \mathrm{a}$ & $17,1 \mathrm{a}$ & $10,5 b$ \\
\hline \multirow[t]{3}{*}{ PST (\%) } & $0-30$ & $0,26 \mathrm{~b}$ & $13,92 \mathrm{a}$ & $0,7 \mathrm{~b}$ & $1,0 \mathrm{~b}$ & $44,4 a$ & $38,7 a$ \\
\hline & $30-60$ & $0,31 \mathrm{~b}$ & $17,13 \mathrm{a}$ & $0,5 b$ & $1,5 b$ & $27,2 \mathrm{a}$ & $33,2 \mathrm{a}$ \\
\hline & $60-90$ & $0,37 \mathrm{~b}$ & $18,06 \mathrm{a}$ & $0,4 \mathrm{~b}$ & $1,5 \mathrm{~b}$ & $32,5 \mathrm{a}$ & $30,3 \mathrm{a}$ \\
\hline \multirow[t]{3}{*}{$\begin{array}{l}\text { Porosidade (\%) } \\
\text { (1) }\end{array}$} & $0-30$ & $-(4)$ & - & $46,9 \mathrm{c}$ & $49,4 \mathrm{c}$ & $47,3 \mathrm{bc}$ & $53,9 a$ \\
\hline & $30-60$ & - & - & $48,7 b$ & $49,7 b$ & $48,5 b$ & $52,2 \mathrm{a}$ \\
\hline & $60-90$ & - & - & $46,7 b$ & $50,2 \mathrm{a}$ & $48,2 \mathrm{ab}$ & $49,1 \mathrm{ab}$ \\
\hline
\end{tabular}

${ }^{(1)}$ Médias seguidas de letras iguais dentro de cada linha não diferem entre si, a $5 \%$ de probabilidade, pelo teste DMS. ${ }^{(2)}$ CE, condutividade elétrica em extrato aquoso 1:2,5 p/v; RAS, razão de adsorção de sódio; PST, percentagem de sódio trocável. ${ }^{(3)}$ Referem-se às propriedades do solo antes da aplicação dos tratamentos. ${ }^{(4)}$ Não avaliado.

Tabela 2. Carbono da biomassa microbiana (Cmic) e relação Cmic/carbono orgânico (Corg) nos solos submetidos aos diferentes tratamentos, nas profundidades de $0-10$ e $10-20 \mathrm{~cm}^{(1)}$.

\begin{tabular}{|c|c|c|c|c|}
\hline \multirow[t]{2}{*}{ Tratamentos $^{(2)}$} & \multicolumn{3}{|c|}{ Cmic ( $\mu \mathrm{g} \mathrm{g}^{-1}$ de solo $)$} & \multirow[t]{2}{*}{ Cmic/Corg (\%) } \\
\hline & Abril/2005 & Agosto/2005 & Março/2006 & \\
\hline \multicolumn{5}{|c|}{ Profundidade $0-10 \mathrm{~cm}$} \\
\hline 1 & $107,24 \pm 2,03 b$ & $89,45 \pm 2,28 \mathrm{c}$ & $131,95 \pm 0,43 b$ & $1,71 \pm 0,23 \mathrm{c}$ \\
\hline 2 & $326,30 \pm 3,28 \mathrm{a}$ & $205,88 \pm 0,22 b$ & $367,73 \pm 9,9 \mathrm{a}$ & $2,65 \pm 0,23 b$ \\
\hline 3 & $34,79 \pm 4,08 \mathrm{c}$ & $45,40 \pm 12,15 \mathrm{c}$ & $135,61 \pm 28,35 b$ & $0,80 \pm 0,23 \mathrm{~d}$ \\
\hline 4 & $236,94 \pm 14,64 \mathrm{a}$ & $464,52 \pm 67,21 \mathrm{a}$ & $276,18 \pm 62,0 \mathrm{a}$ & $3,79 \pm 0,23 \mathrm{a}$ \\
\hline \multicolumn{5}{|c|}{ Profundidade $10-20 \mathrm{~cm}$} \\
\hline 1 & $107,48 \pm 2,38 b c$ & $76,92 \pm 2,03 \mathrm{bc}$ & $252,86 \pm 0,22 \mathrm{a}$ & $2,46 \pm 0,31 \mathrm{a}$ \\
\hline 2 & $160,62 \pm 0,82 \mathrm{ab}$ & $245,78 \pm 3,31 \mathrm{a}$ & $291,82 \pm 1,99 a$ & $2,22 \pm 0,31 \mathrm{a}$ \\
\hline 3 & $78,37 \pm 33,22 \mathrm{c}$ & $64,24 \pm 16,58 \mathrm{c}$ & $150,84 \pm 23,53 b$ & $1,12 \pm 0,31 b$ \\
\hline 4 & $171,60 \pm 2,05 \mathrm{a}$ & $114,54 \pm 19,91 \mathrm{~b}$ & $147,88 \pm 15,93 b$ & $2,48 \pm 0,31 \mathrm{a}$ \\
\hline
\end{tabular}

${ }^{(1)}$ Médias seguidas de letras iguais nas colunas não diferem entre si, a 5\% de probabilidade, pelo "Duncan Test Multiple Range". ${ }^{(2)} \mathrm{T} 1:$ área sem irrigação, coberta com vegetação natural; T2: área sem irrigação, cultivada com erva-sal; T3: área irrigada com rejeito salino durante um ano e cultivada com erva-sal; T4: área irrigada com rejeito salino durante cinco anos e cultivada com erva-sal. 
e os processos radiculares influenciam a composição química da rizosfera. A magnitude dessas alterações é determinada pela quantidade e tipo de $\mathrm{C}$ liberado pela raiz, bem como pelas características intrínsecas do solo. As raízes metabolicamente ativas secretam várias formas de compostos orgânicos. Entre 40 e $95 \%$ do carbono transferido para as raízes é perdido como rizodeposição no solo, o que constitui considerável fluxo de carbono, com influência na modulação da estrutura de comunidades microbianas presentes nesses habitat (Marriel et al., 2005). Portanto, a matéria orgânica e a biomassa microbiana dos solos podem ser alteradas com maior ou menor intensidade, dependendo do sistema de cultivo instalado. No presente estudo, o cultivo da erva-sal aumentou substancialmente o Cmic nas áreas 2 e 4, onde as plantas já se encontravam em pleno desenvolvimento (Tabela 2).

Tabela 3. Coeficiente de correlação de diferentes parâmetros dos solos coletados à profundidade de $0-10$ e $10-20 \mathrm{~cm}^{(1)}$.

\begin{tabular}{|c|c|c|c|c|c|}
\hline Parâmetros & $\mathrm{CE}$ & Cmic & Corg & $\mathrm{N}$ total & P total \\
\hline & \multicolumn{5}{|c|}{ Profundidade de $0-10 \mathrm{~cm}$} \\
\hline $\mathrm{Cmic}$ & $0,33 *$ & -- & $0,46^{*}$ & $0,67 * * *$ & $0,67 * * *$ \\
\hline Fosfatase ácida & ns & ns & $0,95 * * *$ & ns & $0,49 *$ \\
\hline Fosfatase alcalina & ns & $0,49 * *$ & ns & $0,79 * * *$ & $0,75 * * *$ \\
\hline beta-Glucosidase & $-0,57 * * *$ & $0,44 * *$ & $0,44 *$ & $0,86 * * *$ & $0,65 * * *$ \\
\hline Protease & ns & $0,56 * * *$ & $0,54 *$ & $0,90 * * *$ & $0,91 * * *$ \\
\hline L-Asparaginase & $0,47 *$ & $0,44 * *$ & $0,42 *$ & ns & ns \\
\hline \multirow[t]{2}{*}{ L-Glutaminase } & ns & ns & ns & ns & $0,45^{*}$ \\
\hline & \multicolumn{5}{|c|}{ Profundidade de $10-20 \mathrm{~cm}$} \\
\hline $\mathrm{Cmic}^{(2)}$ & ns & -- & $0,52 *$ & & $0,49 *$ \\
\hline Fosfatase ácida & ns & $0,64 * * *$ & $0,81 * * *$ & ns & ns \\
\hline Fosfatase alcalina & ns & ns & ns & $0,80 * * *$ & $0,68 * * *$ \\
\hline$\beta$-Glucosidase & $-0,40^{*}$ & $0,67 * * *$ & $0,52 * *$ & $0,73 * * *$ & $0,88 * * *$ \\
\hline Protease & ns & 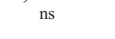 & 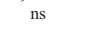 & $0,74 * * *$ & $0,68 * * *$ \\
\hline L-Asparaginase & ns & ns & ns & ns & $-0,50^{*}$ \\
\hline L-Glutaminase & ns & ns & $0,44 *$ & ns & $0,51 *$ \\
\hline
\end{tabular}

${ }^{(1)} \mathrm{CE}$, condutividade elétrica; $\mathrm{Cmic}$, carbono da biomassa microbiana; Corg,

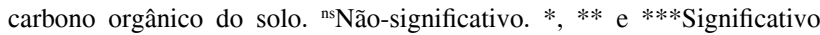
a 5,1 e $0,1 \%$, respectivamente.
A razão Cmic/Corg foi maior na superfície do solo da área 4, seguida da área 2, enquanto que, a $10-20 \mathrm{~cm}$ de profundidade, não houve diferença significativa dessa relação entre as áreas 1, 2 e 4 (Tabela 2). Em média, as razões foram $53 \%$ maiores do que a observada na área 3. A baixa razão observada nessa área indica que houve menor disponibilidade de substrato no solo, provavelmente em razão do reduzido crescimento das plantas ou, ainda, pela menor eficiência de utilização de substrato pelos microrganismos (Yuan et al., 2007). A razão entre o Cmic e o teor de $C$ no solo é uma estimativa indireta da qualidade da matéria orgânica. Quanto menor o valor desta relação, menor deve ser a qualidade da matéria orgânica (Wardle, 1992) e, conseqüentemente, menos eficiente será a biomassa microbiana na imobilização de C. A alta razão $\mathrm{Cmic} / \mathrm{Corg}$, observada nos tratamentos $2 \mathrm{e}$ 4, parece ser um fenômeno transiente ao invés de absoluto e, possivelmente, deveu-se à alocação de fontes de $\mathrm{C}$ prontamente disponíveis, provenientes dos exsudados das plantas, ou pode ter sido conseqüência da adaptação dos microrganismos às condições de alta salinidade (Dilly, 2001; Casamayor et al., 2002).

Os teores de carbono orgânico total, nitrogênio total e fosfato disponível, analisados antes e depois das determinações enzimáticas, estão descritos na Tabela 4. Os teores de $\mathrm{N}$ e $\mathrm{P}$ foram sempre significativamente maiores na área 2 , em ambas as profundidades, enquanto que o teor de $\mathrm{C}$ foi maior, nessa área, apenas na primeira coleta. Esses dados demonstram que a presença da erva-sal melhorou as propriedades químicas do solo e criou um ambiente favorável para a microbiota, o que está de acordo com o observado em seu Cmic.

Os resultados obtidos para as atividades das seis enzimas analisadas se encontram nas Figuras 1 e 2.

Tabela 4. Teores de carbono orgânico, de nitrogênio total e de fósforo do solo, mensurados no início e no final do período experimental ${ }^{(1)}$.

\begin{tabular}{|c|c|c|c|c|c|c|c|c|}
\hline \multirow[t]{2}{*}{ Parâmetros } & \multicolumn{4}{|c|}{ Início do período experimental } & \multicolumn{4}{|c|}{ Final do período experimental } \\
\hline & T1 & $\mathrm{T} 2$ & T3 & $\mathrm{T} 4$ & $\mathrm{~T} 1$ & $\mathrm{~T} 2$ & T3 & $\mathrm{T} 4$ \\
\hline & \multicolumn{8}{|c|}{ Profundidade $0-10 \mathrm{~cm}$} \\
\hline Carbono orgânico & $0,68 b$ & $0,82 \mathrm{a}$ & $0,52 \mathrm{~d}$ & $0,64 \mathrm{c}$ & $0,72 b$ & $1,46 \mathrm{a}$ & $1,48 \mathrm{a}$ & $0,76 b$ \\
\hline Nitrogênio total & $767 b$ & $892 \mathrm{a}$ & $520 \mathrm{c}$ & $575 c$ & $476 c$ & $12,52 \mathrm{a}$ & $465 c$ & $656 \mathrm{~b}$ \\
\hline \multirow[t]{2}{*}{ Fósforo } & $28,3 \mathrm{ab}$ & $34,5 \mathrm{a}$ & $25,4 \mathrm{ab}$ & $13,7 \mathrm{c}$ & $19 \mathrm{c}$ & $129,9 \mathrm{a}$ & $14,4 \mathrm{~d}$ & $22,9 \mathrm{~b}$ \\
\hline & \multicolumn{8}{|c|}{ Profundidade $10-20 \mathrm{~cm}$} \\
\hline Carbono orgânico & $0,68 b$ & $0,87 \mathrm{a}$ & $0,50 \mathrm{~d}$ & $0,61 \mathrm{c}$ & $0,76 \mathrm{c}$ & $1,13 b$ & $1,45 \mathrm{a}$ & $0,73 \mathrm{c}$ \\
\hline Nitrogênio total & $716 b$ & $880 \mathrm{a}$ & $512 d$ & $610 \mathrm{c}$ & $419 \mathrm{c}$ & $825 \mathrm{a}$ & $455 \mathrm{c}$ & $538 \mathrm{~b}$ \\
\hline Fósforo & $25,0 \mathrm{~b}$ & $34,5 \mathrm{a}$ & $16,7 \mathrm{c}$ & $10,1 \mathrm{c}$ & $11,8 \mathrm{c}$ & $56,4 \mathrm{a}$ & $14,3 \mathrm{bc}$ & $15,7 \mathrm{~b}$ \\
\hline
\end{tabular}

${ }^{(1)}$ Médias seguidas de letras iguais, dentro de cada linha, não diferem entre si, a 5\% de probabilidade, pelo teste DMS. ${ }^{(2)}$ T1: área sem irrigação, coberta com vegetação natural; T2: área sem irrigação, cultivada com erva-sal; T3: área irrigada com rejeito salino durante um ano e cultivada com erva-sal; T4: área irrigada com rejeito salino durante cinco anos e cultivada com erva-sal. 
Observou-se que o solo cultivado com erva-sal, sem irrigação (tratamento 2), apresentou os valores mais altos para as atividades enzimáticas mensuradas, o que evidencia a presença, nessa área, de uma microbiota mais ativa. No entanto, o solo sem irrigação com vegetação natural (tratamento 1) apresentou valores e comportamento diferenciado em relação ao cultivado com erva-sal, e chegou a apresentar atividades similares às dos solos que receberam irrigação com rejeito salino,
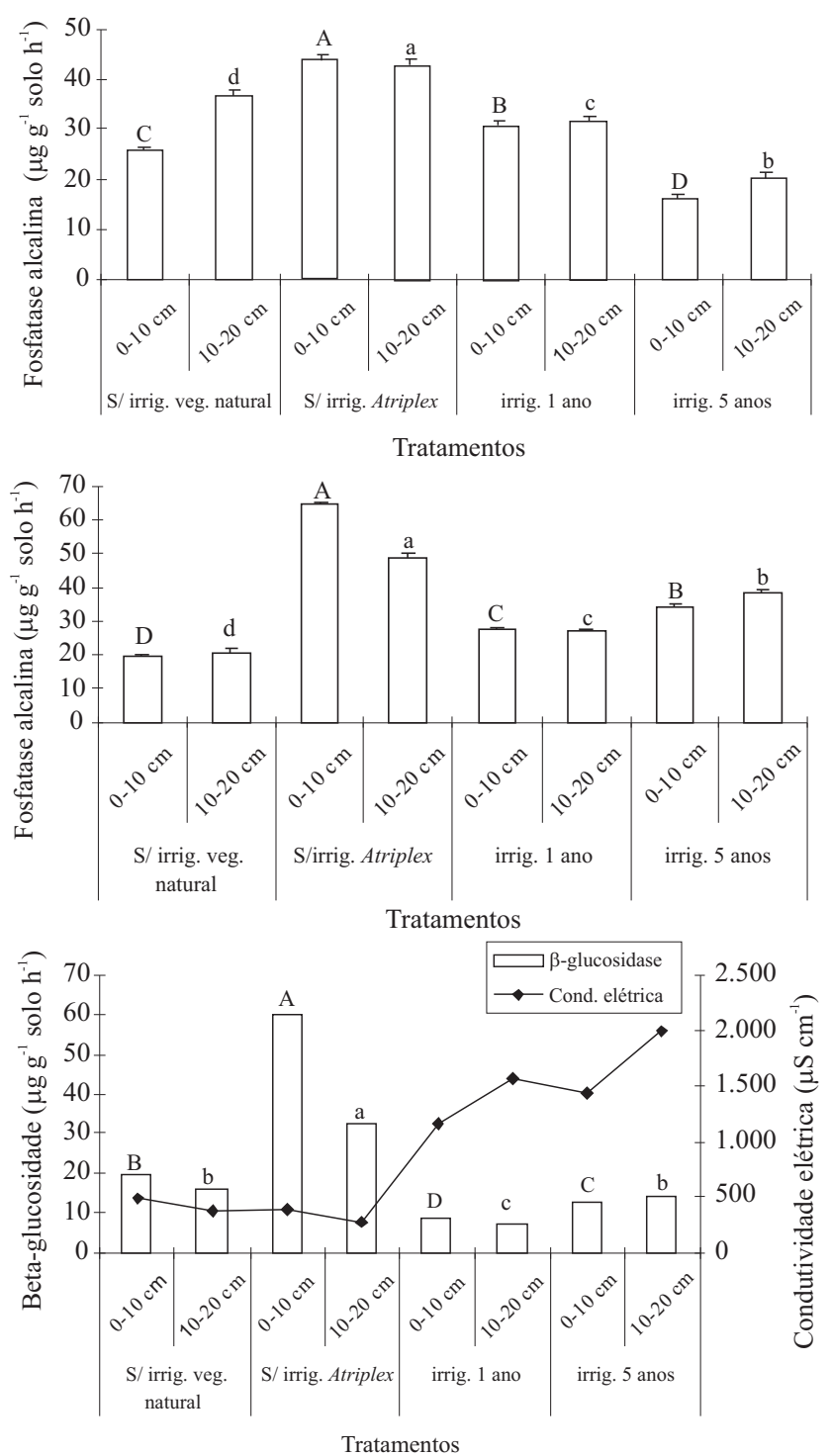

Figura 1. Atividades enzimáticas das fosfatases ácida e alcalina e beta-glucosidase, em solos irrigados ou não com rejeito salino, proveniente do cultivo de tilápia. Médias com letras iguais, maiúscula para $0-10 \mathrm{~cm}$ ou minúscula para $10-20 \mathrm{~cm}$, não diferem entre si, a 5\% de probabilidade, pelo teste DMS. ou significativamente mais baixas, como no caso da fosfatase alcalina. A redução na atividade enzimática indica que a qualidade bioquímica desses solos foi negativamente afetada, provavelmente pelo decréscimo da síntese da enzima, associada à inibição do crescimento microbiano. Além disso, foi observado que, na área 2, com exceção da fosfatase ácida, as demais atividades aumentaram com a profundidade. De maneira geral, o cultivo de erva-sal favoreceu a produção das enzimas, resultados também observados com outras halófitas por Tejada et al. (2006). As diferentes atividades podem ser atribuídas às diferenças na rizodeposição e
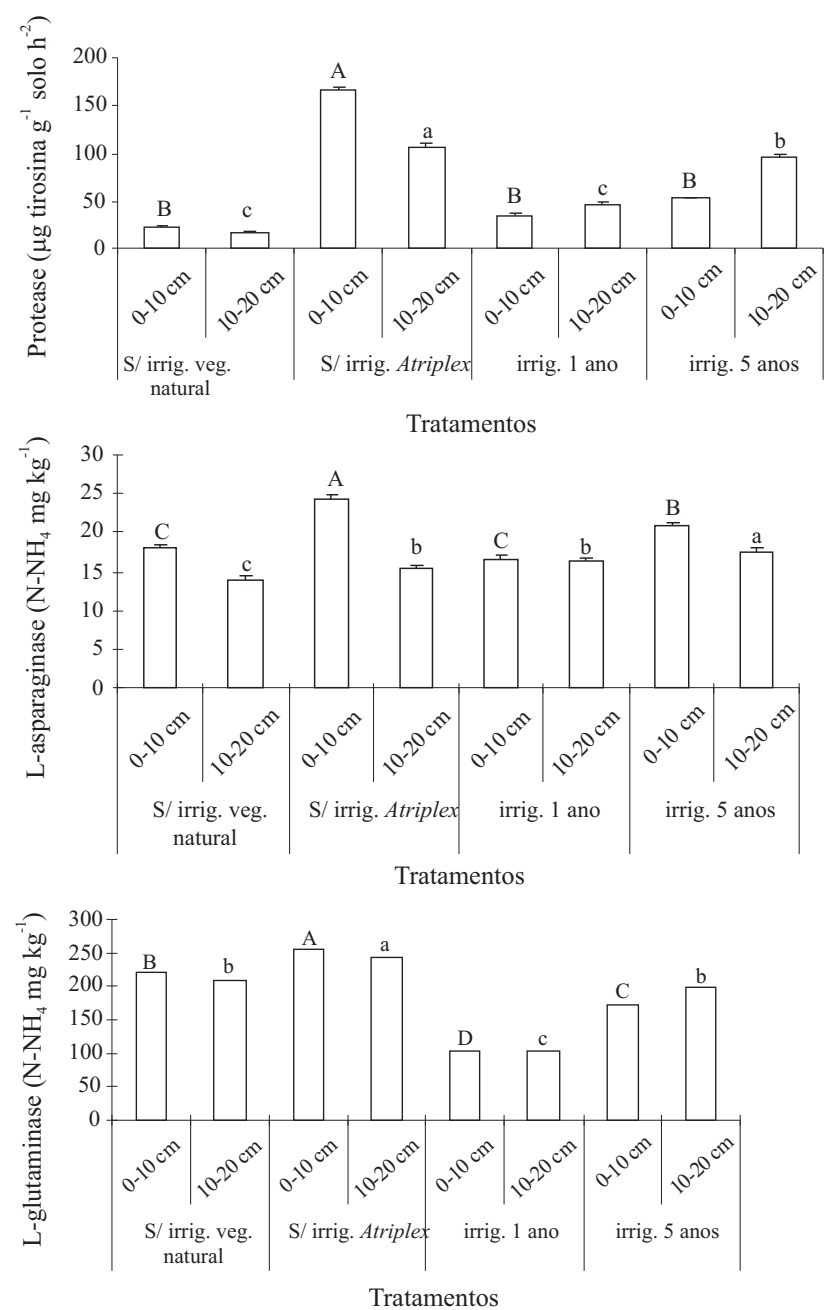

Figura 2. Atividades enzimáticas das protease, L-asparaginase e L-glutaminase, em solos irrigados ou não com rejeito salino, provenientes do cultivo de tilápia. Médias com letras iguais, maiúscula para $0-10 \mathrm{~cm}$ ou minúscula para $10-20 \mathrm{~cm}$, não diferem entre si, a $5 \%$ de probabilidade, pelo teste DMS. 
nos teores de Corg, $\mathrm{P}$ e $\mathrm{N}$, que resultaram em maior diversidade da população microbiana. $\mathrm{O}$ alto valor das atividades enzimáticas demonstra a disponibilidade de quantidades elevadas de substâncias degradáveis. Os exsudados das raízes incluem enzimas e outras substâncias que podem aumentar a disponibilidade de nutrientes no solo (Lambers et al., 2002). Além disso, os exsudados também podem estimular o desenvolvimento de microrganismos na rizosfera (Dakora \& Phillips, 2002).

A correlação significativa entre o Corg e as exoenzimas, com valores de $r$ entre 0,95 e 0,44 (Tabela 3) demonstram que a matéria orgânica pode ter tido papel importante na proteção das enzimas do solo e sua manutenção em formas ativas (Deng \& Tabatabai, 1997).

\section{Conclusões}

1. A irrigação com rejeito da dessalinização, previamente empregado na produção de tilápia, influencia a estrutura do solo, com tendência a torná-lo salino-sódico, mesmo quando cultivado com Atriplex nummularia.

2. A presença da Atriplex nummularia melhora a fertilidade do solo com reflexo nos teores de carbono, fósforo e nitrogênio.

3. As atividades enzimáticas, com exceção da beta-glucosidase, não são afetadas pela salinidade do solo.

4. O cultivo de Atriplex nummularia, em áreas que recebem rejeito salino pela irrigação, melhora a qualidade biológica do solo.

\section{Referências}

ALEF, K.; NANNIPIERI, P. $\beta$-Glucosidase activity. In: ALEF, K.; NANNIPIERI, P. (Ed.). Methods in applied soil microbiology and biochemistry. London: Academic Press, 1995a. p.350-352.

ALEF, K.; NANNIPIERI, P. Protease activity. In: ALEF, K.; NANNIPIERI, P. (Ed.). Methods in applied soil microbiology and biochemistry. London: Academic Press, 1995b. p.313-315.

ALEF, K.; NANNIPIERI, P.; TRAZAR-CEPEDA, C. Phosphatase activity. In: ALEF, K.; NANNIPIERI, P. (Ed.). Methods in applied soil microbiology and biochemistry. London: Academic Press, 1995. p.335-344.

AMORIM, M.C.C. de; PORTO, E.R.; SILVA JÚNIOR, L.G. de A. Evaporação solar como alternativa de reuso dos efluentes da dessalinização por osmose inversa. 2000. Disponível em: $<\mathrm{http}: / /$ www.cepis.org.pe/bvsaidis/aresidua/i-007.pdf $>$. Acesso em: 13 jul. 2004.

AMORIM, M.C.C. de; SILVA JÚNIOR, L.G. de A.; PORTO, E.R. Efeito de sais no solo provenientes do rejeito da dessalinização por osmose inversa no semi-árido pernambucano. In: CONGRESSO BRASILEIRO DE ENGENHARIA AGRÍCOLA, 26., 1997, Campina Grande. Anais. Campina Grande: SBEA, 1997. $1 \mathrm{CD}-\mathrm{ROM}$.

AYRES, R.S.; WESTCOT, D.S. Water quality for agriculture. Rome: FAO, 1985. 174p. (Irrigation and Drainage Paper, 29).

AZEVEDO, C.M. da S.B.; PEDROSA, G.P.; MEDEIROS, J.F. de; NUNES, G.H. de S. Uso do Atriplex nummularia na extração de sais de solos irrigados com efluentes salinos. Revista Brasileira de Engenharia Agrícola e Ambiental, v.9, p.300-304, 2005. (Suplemento).

BALKS, M.R.; BOND, W.J.; SMITH, C.J. Effects of sodium accumulation on soil physical properties under an effluent-irrigated plantation. Australian Journal of Soil Research, v.36, p.821-830, 1998.

CASAMAYOR, E.O.; MASSANA, R.; BENLLOCH, S.; ØVREÅS, L.; DÍEZ, B.; GODDARD, V.J.; GASOL, J.M.; JOINT, I.; RODRÍGUEZ-VALERA， F.; PEDRÓS-ALIÓ, C. Changes in archaeal, bacterial and eukaryal assemblages along a salinity gradient by comparison of genetic fingerprinting methods in a multipond solar saltern. Environmental Microbiology, v.4, p.338-348, 2002.

CHANG, E.H.; CHUNG, R.S.; TSAI, Y.H. Effect of different application rates of organic fertilizer on soil enzyme activity and microbial population. Soil Science and Plant Nutrition, v.53, p.132-140, 2007.

DAKORA, F.D.; PHILLIPS, D.A. Root exudates as mediators of mineral acquisition in low-nutrient environments. Plant and Soil, v.245, p.35-47, 2002.

DENG, S.P.; TABATABAI, M.A. Effect of tillage and residue management on enzyme activities in soils: III. Phosphatases and arylsulphatase. Biology and Fertility of Soils, v.24, p.141-146, 1997.

DILLY, O. Metabolic and anabolic responses of arable and forest soils to nutrient addition. Journal of Plant Nutrition and Soil Science, v.164, p.29-34, 2001.

EMBRAPA. Manual de métodos de análise de solo. 2.ed. Rio de Janeiro: Embrapa-CNPS, 1997. 212p.

EMBRAPA. Sistema brasileiro de classificação de solos. Brasília: Embrapa-SPI, 1999. 412p.

FRANKENBERGER, W.T.; TABATABAI, M.A. L-Asparaginase activity of soils. Biology and Fertility of Soils, v.11, p.6-12, 1991.

FRANKENBERGER JUNIOR, W.T.; TABATABAI, M.A. L-Glutaminase activity of soils. In: ALEF, K.; NANNIPIERI, P. (Ed.). Methods in applied soil microbiology and biochemistry. London: Academic Press, 1995. p.328-330.

HATI, K.M.; BISWAS, A.K.; BANDYOPADHYAY, K.K.; MISRA, A.K. Soil properties and crop yields on a vertisol in India with application of distillery effluent. Soil and Tillage Research, v.92, p.60-68, 2007. 
INFORMAÇÕES sobre a cultura de Artiplex. O que é Atriplex? Disponível em: $<$ http://www.lead.org.br/article/print/209>. Acesso em: 7 fev. 2007.

KILHAM, K. Soil ecology. Cambridge: Cambridge University Press, 1994. 242p.

LAMBERS, H.; JUNIPER, D.; CAWTHRAY, G.R.; VENEKLAAS E.J.; MARTINEZ-FERRI, E. The pattern of carboxylate exudation in Bamksia grandis (Proteaceae) is affected by the form of phosphate added to the soil. Plant and Soil, v.238, p.111-122, 2002.

LIANG, Y.C.; SI, J.; NIKOLIC, M.; PENG, Y.; CHENG, W.; JIANG, Y. Organic manure stimulates biological activity and barley growth in soil subject to secondary salinization. Soil Biology and Biochemistry, v.37, p.1185-1195, 2005.

LIU, Q.M.; WANG, S.J.; PIAO, H.C.; OUYANG, Z.Y. The changes in soil organic matter in a forest-cultivation sequence traced by stable carbon isotope. Australian Journal of Soil Research, v.41, p.1317-1327, 2003.

MAMILOV, A.; DILLY, O.M.; MAMILOV, S.; INUBUSHI, K. Microbial eco-physiology of degrading Aral Sea wetlands: consequences for C-cycling. Soil Science and Plant Nutrition, v.50, p.839-842, 2004.

MARRIEL, I.E.; OLIVEIRA, C.A. de; RAPOSEIRAS, R.; GOMES, E.A.; LANNA, U.G. de P.; CARNEIRO, A.A.; CARNEIRO, N.P. Aplicação da técnica eletroforese em gel de gradiente desnaturante (DGGE) na caracterização de microrganismos dominantes na rizosfera de plantas cultivadas em solo ácido. Sete Lagoas: Embrapa Milho e Sorgo, 2005. 8p. (Embrapa Milho e Sorgo. Circular Técnica, 72).

MINHAS, P.S.; SHARMA, D.R. Hydraulic conductivity and clay dispersion as affected by application sequence of saline and simulated rain water. Irrigation Science, v.63, p.159-167, 1986.

OSTER, J.D.; SHAINBERG, I. Predicting the hydraulic properties of sodic soils. In: INTERNATIONAL SYMPOSIUM ON SALT AFFECTED SOILS - PRINCIPLES AND PRATICES FOR RECLAMATION AND MANAGEMENT, Karnal, 1980. Proceedings. Karnal: Central Soil Salinity Research Institute, 1980. p.195-200.

PEREIRA, S.V.; MARTINEZ, C.R.; PORTO, E.R.; OLIVEIRA, B.R.B.; MAIA, L.C. Atividade microbiana em solo do Semi-Árido sob cultivo de Atriplex nummularia. Pesquisa Agropecuária Brasileira, v.39, p.757-762, 2004.

PESSOA, J.C.C. Análise do desempenho e do impacto ambiental dos dessalinizadores por osmose reversa. 2000. 94p. Dissertação (Mestrado) - Universidade Federal do Ceará, Fortaleza.

PIOTROWSKA, A.; IAMARINO, G.; RAO, M.A.; GIANFREDA, L. Short-term effects of olive mill waste water (OMW) on chemical and biochemical properties of a semiarid Mediterranean soil. Soil Biology and Biochemistry, v.38, p.600-610, 2006.

PORTO, E.R.; AMORIM, M.C.C. de; DUTRA, M.T.; PAULINO, R.V.; BRITO, L.T. de L.; MATOS, A.N.B. Rendimento da Atriplex nummularia irrigada com efluentes da criação de tilápia em rejeito da dessalinização de água. Revista Brasileira de Engenharia Agrícola e Ambiental, v.10, p.97-103, 2006.

PORTO, E.R.; AMORIM, M.C.C. de; SILVA JUNIOR, L.G. de A. Uso de rejeito da dessalinização de água salobra para irrigação da erva-sal (Atriplex nummularia). Revista Brasileira de Engenharia Agrícola e Ambiental, v.5, p.111-114, 2001.

RASUL, G.; APPUHN, A.; MÜLLER, T.; JOERGENSEN, R.G. Salinity-induced changes in the microbial use of sugarcane filter cake added to soil. Applied Soil Ecology, v.31, p.1-10, 2006.

RICHARDS, L.A. (Ed.). Diagnosis and improvement of saline and alkali soils. Washington: United States Salinity Laboratory, 1954. 160p. (Agriculture Handbook, 60).

SARDINHA, M.; MÜLLER, I.T.; SCHMEISKY, H.; JOERGENSEN, R.G. Microbial performance in soils along a salinity gradient under acidic conditions. Applied Soil Ecology, v.23, p.237-244, 2003.

SOARES, T.M.; DUARTE, S.N.; GRAF, C.C.D.; ZANETTI, M.; ZOCCHI, S.S. Produção de mudas cítricas utilizando águas salinas. In: CONGRESSO NACIONAL DE IRRIGAÇÃO E DRENAGEM, 15., 2005, Teresina. Anais. Teresina: ABID, 2005. 1 CD-ROM.

SOARES, T.M.; SILVA, I.J.O. da; DUARTE, S.N.; SILVA, E.F. de F. Destinação de águas residuárias provenientes do processo de dessalinização por osmose reversa. Revista Brasileira de Engenharia Agrícola e Ambiental, v.10, p.730-737, 2006.

TEDESCHI, A.; DELL'AQUILA, R. Effects of irrigation with saline waters, at different concentrations, on soil physical and chemical characteristics. Agricultural Water Management, v.77, p.308-322, 2005.

TEJADA, M.; GARCIA, C.; GONZALEZ, J.L.; HERNANDEZ, M.T. Use of organic amendment as a strategy for saline soil remediation: influence on the physical, chemical and biological properties of soil. Soil Biology and Biochemistry, v.38, p.1413-1421, 2006.

TEJADA, M.; GONZALEZ, J.L. Beet vinasse applied to wheat under dryland conditions affects soil properties and yield. European Journal of Agronomy, v.23, p. 336-347, 2005.

TUCKER, B.M. The determination of exchangeable calcium and magnesium in carbonate soils. Australian Journal of Agricultural Research, v.5, p.706-715, 1954.

VANCE, E.D.; BROOKES, P.C.; JENKINSON, D.S. An extraction method for measuring soil microbial biomass C. Soil Biology and Biochemistry, v.24, p.703-707, 1987.

WARDLE, D.A. A comparative assessment of factors which influence microbial biomass carbon and nitrogen levels in soil. Biology Reviews, v.67, p.321-358, 1992.

WICHERN, J.; WICHERN, F.; JOERGENSEN, R.G. Impact of salinity on soil microbial communities and the decomposition of maize in acidic soils. Geoderma, v.137, p.100-108, 2006.

YUAN, B.C.; LI, Z.Z.; LIU, H.; AO, M.; ZHANG, Y.Y. Microbial biomass and activity in salt affected soils under arid conditions. Applied Soil Ecology, v.35, p.319-328, 2007.

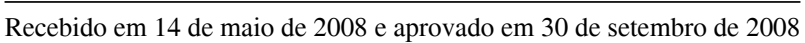

